\title{
A TYPOLOGY OF COMMUNICATION STRATEGIES FOR CORPORATE ADVOCACY
}

\author{
Annette N. Shelby \\ School of Business Administration \\ Georgetown University \\ Washington, D.C.
}

That American business has a poor public image has been well documented.[1] Further, continuing attacks on business in the mass media have no doubt contributed to the negative image. Increasingly, organizations are coming to grips with the image problem and are responding, particularly to media attacks. Corporate advocacy advertising, for example, has received widespread attention.[2] Whatever the medium used and whether by choice or necessity, corporate spokespersons are becoming advocates for their companies' actions and positions.

Though akin to public relations, advocacy goes beyond image building to make a case for, support, or defend the corporate point of view, policies, and actions. Put simply, the focus of advocacy-whether in speeckmaking or op-ed advertising-is argument.[3] Communication strategies provide the framework or structure for argument, prescribe the advocate's options, and thus limit the rhetorical choices to be made. Whereas arguments are situation-specific, strategies may be imposed on the conflict independent of content. Strategies are thus more universal and reflect policy decisions.

This paper presents a conceptual analysis of communication strategies available to the corporate spokesperson. It sets out a typology and describes advantages and disadvantages of the alternatives. Nine types of response patterns are identified here: ignore the attack, withdraw or avoid, sleight-ofhand, confrontation, redefinition of the issues, present company position, confirmation, coalition-building, and proactive advocacy.

\section{Ignoring Attacks}

A traditional way of dealing with hostility toward an organization is to ignore publicly attacks that are made. Since refusing to take notice of an attack can minimize conflict while responding may escalate a controversy, the strategy is sometimes useful in handling assaults on the organization. It does "take two to fight." A disadvantage of the strategy, however, is that silence is a message, which is likely interpreted as relinquishment or guilt. If 
charges go unanswered, they are often assumed to be true. By not answering attacks, the organization may acquiesce to its detractors and their claims.

\section{Withdrawl or Avoidance}

A second strategy useful to advocacy is withdrawl from or avoidance of attack or argument. Though acknowledging that an attack has been made, the advocate chooses not to respond to it. Typical withdrawl or avoidance responses include: "No comment"; "We have no official response to that at this time"; "The President (or whomever) is unavailable for comment."

Advantages of the withdrawal/avoidance strategy are similar to those of ignoring attacks made on the organization. The advocate does not likely escalate the debate or risk putting the organization on the record, particularly in areas that are extremely sensitive for political or legal reasons. Disadvantages of the strategy must also be carefully weighed, however. The "no comment" response may suggest guilt or be interpreted as corporate arrogance, which would have important negative public relations implications. Finally-and perhaps most crucially - the withdrawl/avoidance strategy allows the attacker to draw the issues and present evidence unchallenged.

\section{Sleight-of-Hand}

Sleight-of-hand suggests evading or side-stepping the issue. Typical propaganda techniques fall within the rubric of sleight-of-hand: ad hominem argument or namecalling (shifting the emphasis to the person rather than the argument); bandwagon (everyone is doing it); shifting ground (moving to another and irrelevant issue); hasty generalization (drawing conclusions based on incomplete or unrepresentative data); and emotionalism. The primary characteristic of sleight-of-hand is that it obscures the major issue or point of contention.

Corporate advocates often use sleight-of-hand to side-step indefensible positions. The strategy allows the advocate to focus the discussion on a secondary, perhaps minor or irrelevant issue or fact. Thus, it may diffuse or minimize conflict. The strategy has a number of negative ramifications, however. For one thing, it is ethically questionable. Not only does it avoid the issue, but also it can be personally damaging (as in namecalling or ad hominem argument), incorrect (as in hasty generalization), or misleading (as in shifting ground). Beyond the ethical implications, the strategy is potentially dangerous to use since it only shifts emphasis temporarily. After the sleight-of-hand magic tricks are over, the attacker's position remains substantively unchallenged. Particularly if the issue has been generated by or publicized in the mass media, it will likely resurface-often with even stronger force because of the superficiality or irrelevance of its initial defense. 


\section{Confrontation}

Another strategy organizations are beginning to use to counter attacks leveled against them is to challenge facts and arguments of the opposition or present counter arguments to justify their own position. The successfulness of the confrontative strategy depends on two things: whether the facts and arguments do, in fact, support the organization's position; and, whether the organization can gain access to the necessary media in order to get a hearing for its case.

Corporations have limited access to the mass media, particularly to television and radio. Though companies may buy advertising space in the print media, the national networks prohibit corporate advertising that is issue oriented. Some organizations are investigating alternative channels through which to send their messages. For example, a number of organizations are providing to schools educational materials that include the company viewpoint. Citizens' lobbies are springing up which are protesting such information dissemination.

If organizations are able to get access to necessary media and if their arguments and evidence are convincing to their audiences, they may establish credibility for their position. Further, they may undermine their adversaries, particularly when they are able to prove opposing arguments to be incorrect and evidence factually inaccurate. The challenge, of course, is to disprove the entire case of the opposition. One argument left standing can undermine the corporate case or position.

\section{Redefining the Issues}

Redefining the issues differs from shifting ground in that redefinition aims at a clear understanding and examination of the issues, not an effort to sidestep them. Sometimes issues are drawn in a biased or prejorative manner that renders counteragument unproductive, if not impossible. In such cases, the advocate may choose to redefine the issue or place it into perspective through comparison.

Redefining the issue may mean exposing hidden assumptions or agendas. It may focus on determining the real question being asked or the underlying objection being raised. Often the actual conflict is obscured by secondary or highly emotional issues. Redefinition may be a useful way to uncover the basic point of controversy on its content level. At other times, it calls for separating multiple questions. Occasionally it requires asking questions for clarification.

The major advantage of redefining the issues is that it can lead to a clearer understanding of what the major points of contention are. Further, it tends to focus the controversy on content issues rather than emotional ones. The major disadvantage of the strategy is that it may result in even greater polarization. By clearly drawing the parameters of the conflict, the advocate 
may leave the opposition little maneuverability and may force a commitment to a particular position.

\section{Presenting the Company Position}

Presenting the company position may supplement or serve as an alternative to the strategies of confrontation or redefining the issues. When presenting the company position, the advocate sets out that position point by point, explains reasons for the corporate perspective, and documents company claims. Sometimes the advocate will choose to examine the relative advantages and disadvantages of the company position, a strategy that can be effective in increasing credibility with negative audiences.

Advantages of the "present the company position" strategy are that the advocate has the opportunity to draw the issues and lay the framework, if not ground rules, for debate. Further, by taking the offensive, the spokesperson is more likely to argue the company position from a positive point of view. The major disadvantage of the strategy is that it tends to lack credibility, particularly with negative audiences. The corporate advocate is expected to subscribe to and present the company "line." That "line" is therefore apt to be suspect.

\section{Confirmation}

The strategy of confirmation agrees to the accuracy or legitimacy of the critic's attack but then shifts to a positive discussion of the company's position. A typical confirming response is, "Yes, pollution was a problem; but we've invested heavily in clean-up activities. This is what we're doing...." "You're right, we have had problems in that area" confirms the criticism. "But we're doing something about it" allows the advocate to shift the discussion to the positive things the company is doing.

Advantages of confirmation as a strategy are that it does not place the advocate in the untenable position of defending the indefensible, and it gives the company spokesperson credibility as a trustworthy source. The major disadvantage is that the strategy puts the company on record as agreeing it has done something that is improper. Particularly when legal issues are involved, that position may be dangerous.

\section{Coalition-Building}

Another useful strategy for advocacy is to build coalitions either with organizations with like concerns or, on occasion, with adversaries. The critical factor in coalition-building is to identify commonalities between the organization and those with whom it would seek to work. The tobacco industry has had great success building coalitions with other farm interests 
in influencing legislation. Labor and management have worked from common goals in attempting to rebuild the American automobile industry.

The major advantage to coalition-building is that by focusing on agreement, polarization may be minimized. The major disadvantage is that disagreement may be forced below the surface where it can fester and grow. Coalition-building will be successful to the extent that common goals are more silent than the individual goals of either party involved.

\section{Proactive Approach}

Historically, American corporations have felt little need to explain themselves or their policies to the public, even in the face of fierce antimonopolistic and trade union pressures. The consumer movement, however, along with the influence of the mass media's reporting on issues of public concern, has brought the corporation's business into the public's living rooms. Consequently, American business is being required to justify its policies.

Corporate representatives are often unprepared for the hostility and conflict they encounter. They do not anticipate the public uproar that accompanies controversial policy decisions and have little experience and less confidence in dealing with the underlying value conflicts that erupt. In their efforts to defend their organizations, they are often frustrated, confused, and misunderstood.

An alternative to the traditional defensive, reactive approaches to advocacy is a proactive strategy that suggest the necessity of corporate intervention before opposition has crystallized or become vocal. The proactive approach - both preemptive and preventative-involves a minimum of four steps: 1) anticipate questions likely to be raised about the organization and its policies; 2) research the facts, precedents, and implications of corporate policy; 3) develop a public relations and advocacy campaign before systematic and damaging attacks begin; and 4) monitor the results of the campaign.

The advocacy plan should be well conceived and comprehensively developed. It should identify the audience to be targeted, specify commonalities between the organization and its potential critics, adapt its message to the targeted audience, determine media to be used, develop a timetable, and include plans for implementation.

The advantages of such a proactive stance are obvious: the image problems minimized; the arguments answered before they are allowed to escalate into major points of controversy; the advocate's favorable position gained from drawing the issues. The major disadvantage of the approach is that the organization may invite criticism and argument that may not have otherwise been a priority for its critics.

A final caveat: The strategies an organization chooses for advocacy depend to a great extent on the managerial style and orientation of the organization's chief decision-makers. Some executive officers are sensitive to the 
need for good corporate public relations and support proactive advocacy campaigns. Others view advocacy as a stop-gap, "putting out fires" role. Ultimately, the advocate can do little without support from the top. And that is a managerial policy decision.

\section{References}

1. The Opinion Research Corporation, cited in David Liff, Mary O'Connor, and Clarke Bruno, Corporate Advertising: The Business Response to Changing Public Attitudes (Washington D.C.: Investor Responsibility Research Center, October, 1980).

2. Ethics and Advocacy Advertising, Business Ethics Report (Bentley College, Waltham, MA: Center for Business Ethics, 1978); S. Prakash Sethi, "Advocacy Advertising in America," Keynote Address at Advocacy Advertising Conference, Toronto, November 25, 1981; S. Prakash Sethi, Advocacy Advertising and Large Corporations (Lexington, MA: D.C. Health, 1977).

3. David Thomas, "Corporate Advocacy: Development in Forensics," Speech Communication Association National Convention, Anaheim, CA, November, 1981; Robert L. Heath, "Corporate Advocacy: An Application of Speech Communication Perspectives and Skills-and More," Communication Education, 19 (September 1980), pp. 370-1. 